\title{
UV-AUC Spectrophotometric Method for Quantitative Estimation of Teneligliptin
}

\section{Pritam S Jain*, Prafulla M Patil, Savita J Sonawane and Sanjay J Surana}

R.C. Patel Institute of Pharmaceutical Education and Research, Karwand Naka, Shirpur, India

*Corresponding Author: Pritam S Jain, R.C. Patel Institute of Pharmaceutical Education and Research, Karwand Naka, Shirpur, India.

Received: April 10, 2019; Published: May 06, 2019

DOI: $10.31080 /$ ASPS.2019.03.0274

\begin{abstract}
Objective: The main objective of this work is to establish a simple, rapid, accurate and economical spectrophotometric method has been developed for estimation of teneligliptin in bulk and pharmaceutical formulation.

Material and Method: The $\lambda$ max of teneligliptin in methanol: water (50:50) was found to be $245 \mathrm{~nm}$. The area under curve (AUC) spectrum was recorded between $232.80 \mathrm{~nm}$ to $258.60 \mathrm{~nm}$. The accuracy of the method was checked by recovery experiment performed at three different levels i.e, $80 \%, 100 \%$ and $120 \%$. The precision of the method was studied as an intra-day, inter-day variation and repeatability. Ruggedness of the proposed method was studied with the help of two analysts.

Results: The drug followed linearity in the concentration range 10-35 $\mathrm{g} / \mathrm{ml}$ with correlation coefficient value ( $\mathrm{r}^{2}$ ) 0.999 . The proposed method was applied to pharmaceutical formulation and \% amount of drug estimated $97.2 \%$ was found in good agreement with the label claim. The \% recovery was found to be in the range $97.78 \%-98.12 \%$. The low value of \% R.S.D. was indicative of the accuracy and reproducibility of the method. The \% R.S.D. value of precision method less than 2 indicated that the method was precise. Conclusion: The above method was a rapid and cost effective quality control tool for routine analysis of teneligliptin bulk and in pharmaceutical dosage form. This UV spectrophotometric technique is quite simple, accurate, precise, reproducible and sensitive. The validation procedure confirms that this is an appropriate method for their quantification in the plant material and formulation. It is also used in routine quality control of the raw materials as well as formulations.
\end{abstract}

Keywords: Teneligliptin; UV-Spectrophotometric; Quantitative Determination; Validation, AUC

\section{Introduction}

Teneligliptin is chemically $\{(2 s, 4 s)-4-[4-(3-M e t h y l-1-p h e-$ nyl-1-H pyrazole-5-yl) piperazin-1-yl] pyrrolidin-2-yl\} (1,3-thiazolidin-3-yl) methanone (Figures 1,2,3), having molecular formula:C17H27NO4, with a molecular mass of $309.40 \mathrm{~g} / \mathrm{mol}$. Teneligliptin is a Type-2 diabetismellitus drug that belongs to dipeptidyl peptidase-4 inhibitors or "gliptins". It appears to have potent, sustained effects on glycemic control, thereby reducing the complications oh hypoglycaemia and postprandial hyperglycemia. Glucagon like peptidase (GLP-1) a peptidase secreted from the GIT in response to food ingestion increase insulin secretion and suppresses glucagon secretion from the pancreas, there by playing an

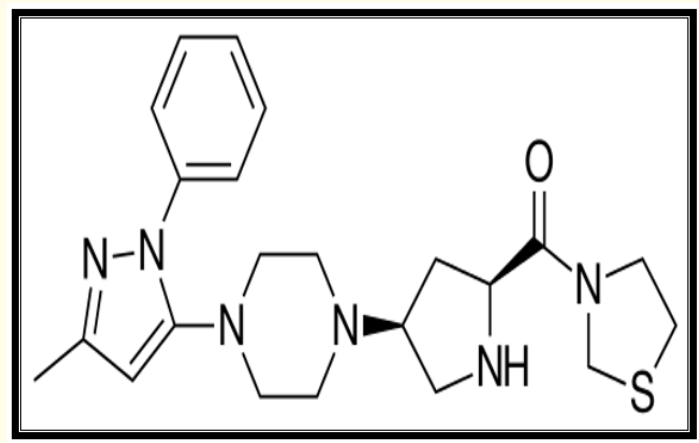

Figure 1: Chemical structures of Teneligliptin. important role in controlling postprandial blood glucose level. 


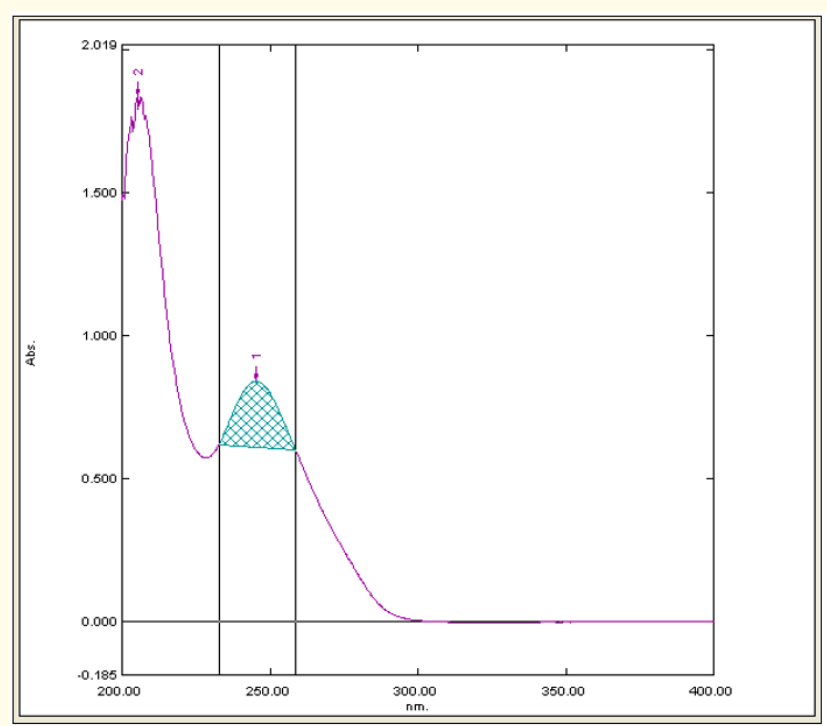

Figure 2: UV-AUC spectra of Teneligliptin.

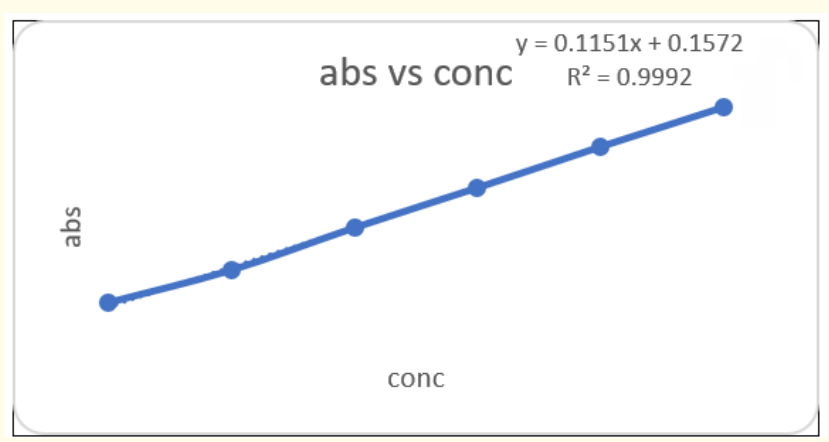

Figure 3: Linearity curve of Teneligliptin.

Analysis part is an important from formulation development of any drug molecule. A suitable and validated method should be vacant for the drug delivery system for analysis of bulk drug and formulation. Various methods are reported for the analysis of individual drug as HPLC and LCMS/MS but no spectrophotometric method is reported estimation of drug in pharmaceutical dosage form. Accordingly, the objective of this study is to develop and validate the spectrophotometric method for the estimation of teneligliptin in bulk and pharmaceutical formulation as per ICH guidelines.

\section{Material and Method}

Teneligliptin was supplied as a gift sample by Ipca laboratory, Mumbai. Tablets of $20 \mathrm{mg}$ strength were purchased from the local pharmacy in Mumbai under commercial available brand name
Teneza (Glenmark pharmaceutical Ltd.), tablets were used as pharmaceutical formulation for further analysis.

\section{Instrument}

A double beam UV-VIS spectrophotometer (UV-2450, Shimadzu, Japan) connected to a computer loaded with spectra manager software UV Probe 2.21 with $10 \mathrm{~mm}$ quartz cells was used. The spectra were obtained with the instrumental parameters as follows: Wavelength range: 400-200nm; scan speed: Medium; sampling interval: $1.0 \mathrm{~nm}$. All weights were taken on an electronic balance (Model Shimadzu AUX 120).

Preparation of stock standard solution and selection of wavelengths

Accurately weighed $10 \mathrm{mg}$ was transferred to $100 \mathrm{ml}$ volumetric flask, dissolved in $100 \mathrm{ml}$ methanol: water (50:50) to obtain a concentration of $100 \mu \mathrm{g} / \mathrm{mL}$. From it, an appropriate concentration of $10 \mu \mathrm{g} / \mathrm{mL}$ was prepared and scanned in the UV-visible range 400$200 \mathrm{~nm}$; teneligliptin showed a maximum absorbance at $245 \mathrm{~nm}$.

\section{Validation of the method}

\section{Study of linearity}

From the stock standard solution, an appropriate amount of aliquots portion in the range of 1-3.5 mL were transferred into a series of $10 \mathrm{~mL}$ volumetric flasks and diluted up to mark using the methanol: water (50:50) solvent to obtain a concentration in the range of $10-35 \mu \mathrm{g} / \mathrm{mL}$. The solutions were scanned on a spectrophotometer in the range of 400-200 nm. The calibration plot was constructed as concentration vs. absorbance.

\section{Accuracy}

To the preanalyzed sample solutions, a known amount of standard stock solution was added at different levels i.e. $80 \%, 100 \%$ and $120 \%$. The solutions were reanalyzed by proposed method.

\section{Precision}

Precision of the method was studied as intra-day and inter-day variations. Intra-day precision was determined by analyzing the 10,20 and $30 \mu \mathrm{g} / \mathrm{ml}$ of teneligliptin solutions for three times in the same day. Inter-day precision was determined by analyzing the 10 , 20 and $30 \mu \mathrm{g} / \mathrm{ml}$ of teneligliptin solutions daily for three days over the period of week.

\section{Sensitivity}

The sensitivity of measurements of teneligliptin the use of the proposed methods was estimated in terms of the limit of quantification (LOQ) and the limit of detection (LOD). The LOQ and LOD 
were calculated using equation $\mathrm{LOD}=3.3 \times \mathrm{N} / \mathrm{B}$ and $\mathrm{LOQ}=10 \times \mathrm{N} / \mathrm{B}$, where $N^{\prime}$ is the standard deviation of the AUC of the drugs $(n=3)$, taken as a measure of noise, and ' $\mathrm{B}$ ' is the slope of the corresponding calibration curve.

\section{Repeatability}

Repeatability was determined by analyzing $20 \mu \mathrm{g} / \mathrm{ml}$ concentration of teneligliptin solution for six times.

Ruggedness

Ruggedness of the proposed method was determined for $15 \mu \mathrm{g} /$ $\mathrm{ml}$ concentration of teneligliptin by analysis of aliquots from homogenous slot by two analysts using same operational and environmental conditions.

Application of proposed method for pharmaceutical formulation:

Twenty tablets were accurately weighed, average weight determined and ground into fine powdered. A quantity of powder equivalent to $10 \mathrm{mg}$ was transferred into a $100 \mathrm{~mL}$ volumetric flask, the volume was adjusted to the mark using the solvent. An appropriate volume $2 \mathrm{~mL}$ was transferred into a $10 \mathrm{~mL}$ volumetric flask and the volume was adjusted to the mark to obtain the desired concentration of $20 \mu \mathrm{g} / \mathrm{mL}$.

\section{Determination of teneligliptin in bulk}

A quantity of powder equivalent to $10 \mathrm{mg}$ was transferred into a $100 \mathrm{~mL}$ volumetric flask, the volume was adjusted to the mark using the methanol solvent. An appropriate volume $2 \mathrm{~mL}$ was transferred into a $10 \mathrm{~mL}$ volumetric flask and the volume was adjusted to the mark to obtain the desired concentration of $20 \mu \mathrm{g} / \mathrm{mL}$.

\section{Results and Discussion}

\section{Method validation}

The proposed method was validated as per ICH guidelines. The solutions of the drugs were prepared as per the earlier adopted procedure given in the experiment.

Linearity studies

The linear regression data for the calibration curves showed good linear relationship over the concentration range $10-35 \mu \mathrm{g} / \mathrm{ml}$ for teneligliptin. Linear regression equation was found to be $\mathrm{Y}=$ $0.115 \mathrm{X}+0.157\left(\mathrm{r}^{2}=0.999\right)$. The result is expressed in table 1 and 2 .

\begin{tabular}{|l|c|}
\hline Parameters & Method \\
\hline Linearity range $(\mu \mathrm{g} / \mathrm{ml})$ & $10-35$ \\
\hline Selected range $(\mathrm{nm})$ for AUC & $232.80-258.60$ \\
\hline Slope & 0.115 \\
\hline Intercept & 0.157 \\
\hline Correlation coefficient & 0.999 \\
\hline Limit of detection $(\mu \mathrm{g})$ & 6.1779 \\
\hline Limit of quantification $(\mu \mathrm{g})$ & 18.7209 \\
\hline
\end{tabular}

Table 1: Optical characteristics and linearity data of Teneligliptin.

\begin{tabular}{|c|c|c|c|}
\hline Sr. no. & $\begin{array}{c}\text { Concentration } \\
(\boldsymbol{\mu} \mathbf{g} / \mathbf{m l})\end{array}$ & $\begin{array}{c}\text { Absorbance } \\
\text { Mean } \pm \text { S.D }\end{array}$ & \%R.S.D \\
\hline 1 & 10 & $0.2785 \pm 0.003536$ & 1.269492 \\
\hline 2 & 15 & $0.3765 \pm 0.002121$ & 0.563432 \\
\hline 3 & 20 & $0.5025 \pm 0.002121$ & 0.422153 \\
\hline 4 & 25 & $0.611 \pm 0.001414$ & 0.229208 \\
\hline 5 & 30 & $0.733 \pm 0.001414$ & 0.192935 \\
\hline 6 & 35 & $0.847 \pm 0.003536$ & 0.417172 \\
\hline
\end{tabular}

Table 2: linearity study of Teneligliptin.

\section{Accuracy}

The \% recovery of teneligliptin was found at three concentration level 80, 100 and 120\%. Result shown in table 3.

\begin{tabular}{|l|c|c|c|c|}
\hline \% Value & $\begin{array}{c}\text { Amount } \\
\text { of drug } \\
\text { added( } \boldsymbol{\mu g} / \\
\mathbf{m l})(\mathbf{n}=\mathbf{3})\end{array}$ & $\begin{array}{c}\text { Amount } \\
\text { found } \\
(\boldsymbol{\mu g} / \mathbf{m l}) \\
(\mathbf{n = 3})\end{array}$ & \% Recovery & \% RSD \\
\hline 80 & 27 & 26.401 & 97.7814 & 1.32557 \\
\hline 100 & 30 & 29.385 & 97.9500 & 1.15261 \\
\hline 120 & 33 & 32.38 & 98.1212 & 0.97087 \\
\hline
\end{tabular}

Table 3: Accuracy.

Average of three estimations

\section{Precision}

The precision of the developed method was determined in terms of \% relative standard deviation (\% RSD). The \% R.S.D. values were found to be less than 2 . Result shown in table 4 . 


\begin{tabular}{|l|c|c|}
\hline \multirow{2}{*}{ Concentration } & $\begin{array}{c}\text { Intra-day precision } \\
\text { (n=3) }\end{array}$ & $\begin{array}{c}\text { Inter-day precision } \\
\text { (n=3) }\end{array}$ \\
\cline { 2 - 3 } & Amount found \%RSD & $\begin{array}{c}\text { Amount found } \\
\text { \%RSD }\end{array}$ \\
\hline \multirow{2}{*}{10} & 9.725 & 9.724 \\
& 1.3257 & 1.3634 \\
\hline \multirow{2}{*}{20} & 19.502 & 19.492 \\
& 1.1526 & 0.8952 \\
\hline \multirow{2}{*}{30} & 29.274 & 29.264 \\
& 0.9708 & 0.4773 \\
\hline
\end{tabular}

Table 4: Precision.

Average of three estimations

\section{Sensitivity}

The sensitivity of the method was performed in terms of Limit of Detection (LOD) and Limit of Quantification (LOQ). The LOQ and LOD for teneligliptin were found to be $0.281 \mu \mathrm{g}$ and $0.365 \mu \mathrm{g}$, respectively.

\section{Repeatability}

Repeatability was determined by analyzing $20 \mu \mathrm{g} / \mathrm{mL}$ concentrations of teneligliptin solution for six times and the \% amount determined with $\% \mathrm{RSD}<2$ for both the methods. The results are expressed in table 5.

\begin{tabular}{|l|c|c|c|}
\hline Component & $\begin{array}{c}\text { Amount taken } \\
(\boldsymbol{\mu g} / \mathbf{m l})(\mathbf{n}=6)\end{array}$ & $\begin{array}{c}\text { Amount found } \\
(\mathbf{\%})(\mathbf{n}=6)\end{array}$ & \%RSD \\
\hline Teneligliptin & 20 & $97.515 \pm 0.0051$ & 1.03273 \\
\hline
\end{tabular}

Table 5: Repeatability.

Average of Six estimations

\section{Ruggedness}

The method was performed by changing the condition of the method for the same concentration. The \%RSD was found less than 2. The results were given in table 6 .

\begin{tabular}{|l|c|c|}
\hline Component & Amount taken $(\boldsymbol{\mu g} / \mathbf{m l})$ & Amount found (\%) \\
\hline & $(\mathrm{n}=3)$ & Analysis $1 \pm \mathrm{SD}$ \\
& & Analysis $2 \pm \mathrm{SD}$ \\
\hline \multirow{2}{*}{ Teneligliptin } & 15 & $97.4933 \pm 0.0025$ \\
& & $97.4733 \pm 0.0020$ \\
\hline
\end{tabular}

Table 6: Ruggedness.

Average of three estimations
Determination of teneligliptin in Bulk

The $\%$ amounts reveal from in-house tablet, that there is no interruption from excipients present in it. The \% amount for all the method was determined results shown in table 7.

\begin{tabular}{|l|c|c|c|}
\hline $\begin{array}{l}\text { Concentration } \\
(\boldsymbol{\mu g} / \mathbf{m l})(\mathbf{n}=\mathbf{6})\end{array}$ & $\begin{array}{c}\text { Amount found } \\
(\boldsymbol{\mu g} / \mathbf{m l})(\mathbf{n}=\mathbf{6})\end{array}$ & $\begin{array}{c}\text { Amount found } \\
\mathbf{( \% )}\end{array}$ & \% RSD \\
\hline 20 & 19.498 & 97.49 & 0.6278 \\
\hline
\end{tabular}

Table 7: Determination of Teneligliptin in Bulk. Average of six estimations

Application of proposed method for pharmaceutical formulation

The spectrum was recorded at $245 \mathrm{~nm}$. The concentrations of the drug were calculated from linear regression equation. The $\%$ amount was found between $97.49 \%$ to $100.00 \%$ in table 8 and table 9 [1-8].

\begin{tabular}{|l|c|c|c|}
\hline $\begin{array}{l}\text { Concentration } \\
(\boldsymbol{\mu g} / \mathbf{m l})(\mathbf{n}=6)\end{array}$ & $\begin{array}{c}\text { Amount found } \\
(\boldsymbol{\mu g} / \mathbf{m l})(\mathbf{n}=6)\end{array}$ & $\begin{array}{c}\text { Amount } \\
\text { found (\%) }\end{array}$ & \% RSD \\
\hline 20 & 19.445 & 97.225 & 1.9791 \\
\hline
\end{tabular}

Table 8: Analysis of pharmaceutical formulation. Brand name- Teneza 20mg (Glenmark.).

Average of six estimations

\begin{tabular}{|c|c|}
\hline Concentration & Area \\
\hline 10 & 1.728 \\
\hline 15 & 1.818 \\
\hline 20 & 2.223 \\
\hline 25 & 2.247 \\
\hline 30 & 3.148 \\
\hline 35 & 3.487 \\
\hline
\end{tabular}

Table 9: Analysis the area under curve.

\section{Conclusion}

This UV spectrophotometric technique is quite simple, accurate, precise, reproducible and Sensitive. The validation procedure confirms that this is an appropriate method for their quantification in the Bulk and formulation. It is also used in routine quality control of the raw materials as well as formulations containing this entire compound. 
Acknowledgments

The authors are thankful to the Principal and management, R.C. Patel Institute of Pharmaceutical Education and Research, Shirpur (M.S.), India for providing the required facilities to carry out this research work.

\section{Bibliography}

1. T. Yoshida. Bioorganic and Medicinal Chemistry 20 (2012): 5705-5719.

2. Kishimoto M. "Teneligliptin: a DPP-4 inhibitor for the treatment of type-2 diabetes". Diabetes, Metabolic Syndrome and Obesity: Targets and Therapy 6 (2013): 187-195.

3. Goda M. "Teneligliptin for treatment of type 2 diabetes". Pub. Med 49.10 (2013): 615-629.

4. Evaluation and Licensing Division, Pharmaceutical and Food Safety Bureau, Ministry of Health, Labour and Welfare (2012).

5. Ryuichi M and Hironori N. "Teneligliptin: expectations for its pleiotropic action". Expert Opinion on Pharmacotherapy 16.3 (2015): 417-426.

6. Miyako K. "Teneligliptin: A DPP4 inhibitor for the treatment of type 2 diabetes". Dove Medical Press 6 (2013): 187-195.

7. Ashim Kumar Sen. Journal of Applied Pharmaceutical Science 6 (2016): 157-165.

8. ICH-Guidelines Q2 (R1), Validation of Analytical Procedures: Text and Methodology. (2005).

\section{Volume 3 Issue 6 June 2019}

(C) All rights are reserved by Pritam S Jain., et al. 